\title{
“CAMINANTE, NO HAY CAMINO, SE HACE CAMINO AL ANDAR": UM ESTUDO SOBRE A CONSTRUÇÃO DE SENTIDOS EM ESTRATÉGIA
}

\section{RESUMO}

Este estudo sugere o construcionismo social como abordagem metodológica útil na compreensão da estratégia enquanto prática social. Para esse propósito, são apresentados os resultados da análise de entrevistas conduzidas com proprietários, sócios de empresas e executivos sobre os sentidos atribuídos às práticas de estratégia em suas organizações. $\mathrm{O}$ objetivo foi investigar como praticantes da estratégia constroem o entendimento sobre o que é estratégia, sobre como ela é criada nas organizações e sobre quem são os envolvidos nesta criação. Foram realizadas entrevistadas em profundidade com 23 executivos/donos de empresas que atuam com a estratégia no seu dia a dia profissional. Interpretando os repertórios linguísticos dos participantes da pesquisa, por meio da abordagem metodológica do construcionismo social, os resultados mostraram uma diversidade de entendimentos para os temas "o que é estratégia" e "como a estratégia é criada". Concluiu-se que a valorização social da palavra estratégia foi um fator decisivo para sua difusão, especialmente entre pequenas empresas, pois o uso da palavra estratégia legitima os membros de uma organização a demonstrarem que atuam como bons gestores e dá sentido a ações que sempre existiram no espaço organizacional.

Palavras-chave: Construcionismo social; Estratégia como prática; Sentidos em estratégia.

\section{“CAMINANTE, NO HAY CAMINO, SE HACE CAMINO AL ANDAR": A STUDY ON THE CONSTRUCTION OF MEANINGS IN STRATEGY}

\begin{abstract}
This study suggests the social construcionism approach as useful methodological approach to comprehend strategy as a social practice. For this purpose the results of interviews conducted with owners, business partners and executives are presented regarding the meanings attributed to the practice of strategy in their organizations. The aim was investigate how strategic practitioners build strategic understanding of what strategy is, how it is created in organizations and who are involved in its creation. We develop depth interviews with 23 executives/business owners who work with the strategy in their professional life. Interpreting their linguistic repertoires, through the methodological approach of social constructionism, the results showed a diversity of understandings for the themes "what is strategy" and "how the strategy is created". The study concluded that the social value of the word strategy was one factor in its spread, especially among small businesses, because the use of the word strategy legitimates the members of an organization to demonstrate that they act as good managers and gives meaning to actions that have always existed in the organizational space.
\end{abstract}

Keywords: Strategy as Practice; Social Construcionism; Meanings in Strategy. 


\section{“CAMINANTE, NO HAY CAMINO, SE HACE CAMINO AL ANDAR": UN ESTUDIO SOBRE LA CONSTRUCCIÓN DE SIGNIFICADOS EN ESTRATEGIA}

\section{RESUMEN}

Este estudio sugiere que el enfoque de construcción social como enfoque metodológico útil para comprender la estrategia como práctica social. Para ello se presentan los resultados de las entrevistas realizadas a los propietarios, socios de negocios y ejecutivos con respecto a los significados atribuidos a la práctica de la estrategia en sus organizaciones. El objetivo era investigar cómo los profesionales de estratégica construyen la comprensión estratégica de lo que la estrategia es, cómo se crea en las organizaciones y que están involucrados en su creación. Desarrollamos entrevistas en profundidad con los propietarios de 23 ejecutivos / de negocios que trabajan con la estrategia en su vida profesional. Interpretación de sus repertorios lingüísticos, a través del enfoque metodológico del construccionismo social, los resultados mostraron una diversidad de interpretaciones de los temas "¿Qué es estrategia" y "cómo se crea la estrategia"?. El estudio concluyó que el valor social de la estrategia de la palabra fue un factor en su propagación, especialmente entre las pequeñas empresas, ya que el uso de la estrategia de la palabra legitima los miembros de una organización para demostrar que actúan como buenos gestores y dan sentido a las acciones que siempre han existido en el espacio organizacional.

Palabras clave: Estrategia como la Práctica; Construcción Social; Significados de Estrategia.

Fábio Figueiredo Biselli ${ }^{1}$ Maria José Tonelli ${ }^{2}$ André Luis Silva ${ }^{3}$

\footnotetext{
${ }^{1}$ Mestre em Administração de Empresas pelo Fundação Getúlio Vargas - FGV. Diretor da IT Marketing S/C Ltda. Brasil.E-mail: fbiselli@uol.com.br

${ }^{2}$ Doutora em Psicologia Social pela Pontifícia Universidade Católica de São Paulo - PUC/SP. Professora da Escola de Administração de Empresas de São Paulo da Fundação Getúlio Vargas - Eaesp/FGV e coordenadora do Núcleo de Estudos em Organizações e Pessoas - Neop. Brasil. E-mail: maria.jose.tonelli@ @gv.br

${ }^{3}$ Doutor em Administração de Empresas e Professor da Escola de Administração de Empresas de São Paulo da Fundação Getúlio Vargas - Eaesp/FGV. Pesquisador do Núcleo de Estudos em Organizações e Pessoas - Neop. Brasil. E-mail: andre.luis.silva@fgv.br
} 


\section{INTRODUÇÃO}

Por que no interior das organizações os indivíduos tomadores de decisão tendem a utilizar a palavra estratégia para produzirem o sentido desejado acerca de uma ação que buscam implantar? O que os conduzem a essa escolha e maneira de falar? Como são construídos os sentidos da estratégia no contexto organizacional? E quem são os envolvidos em sua legitimação? Diante desse conjunto variado de questões, discutir como os significados da estratégia são criados e moldados no contexto organizacional é uma forma de evidenciar que a gestão, em si, reflete uma construção social e histórica legitimada por meio dos sentidos atribuídos às práticas organizacionais pelos agentes envolvidos em sua realização (Clark, 2007; Wenyao; Watson, 2008; Kumar \& Dash, 2011).

Neste artigo, sugerimos o construcionismo social como abordagem metodológica útil na compreensão da estratégia enquanto uma prática social. Este enfoque mostra-se como uma abordagem teóricometodológica útil para repensar certa "autonomia" que a área de Estratégia parece ter alcançado na esfera acadêmica (Varyani \& Khammar, 2010; Tureta \& Lima, 2011; Valadão e Silva, 2012; Maciel \& Augusto, 2013). Ou seja, na medida em que esta área se direcionou a produzir estudos de cunho mais generalistas e imparciais para aplicação em diferentes organizações, a produção de conhecimento sobre esse assunto acabou se distanciando do cotidiano das organizações e do entendimento sobre as múltiplas redes de relações que constituem suas especificidades no contexto social (Whittington, 1993).

Considerando que esse distanciamento do social está vinculado a um modelo de ciência "hard" que tende a negligenciar a humanidade presente no âmbito da gestão, neste artigo, discutimos a construção do sentido da palavra estratégia nas organizações, para evidenciar os múltiplos sentidos e as relações sociais que permeiam todo esse processo. Assim sendo, o objetivo desta pesquisa é investigar como praticantes de estratégia constroem o entendimento sobre o que é estratégia, sobre como ela é criada nas organizações e sobre quem são os envolvidos nesta criação. Para alcançar este objetivo, realizamos entrevistas com proprietários, sócios de empresas e executivos, sobre os sentidos atribuídos por eles às práticas de estratégia em suas organizações. A abordagem teórico-metodológica utilizada é a socioconstrucionisma (Spink, 1999; Cunliffe, 2008) e a proposta de Weick (1995) também é utilizada para apreender a construção de sentidos nas organizações.

Após esta breve introdução, este trabalho segue estruturado da seguinte maneira: na próxima seção, estando coerente com a abordagem construcionista, apresentamos o escopo histórico da estratégia enquanto campo de pesquisa. Em seguida, esclarecemos a abordagem da estratégia enquanto prática social. Posteriormente, detalhamos a abordagem teóricometodológica adotada na realização deste trabalho. Finalizamos com a articulação dos resultados empíricos obtidos no estudo e, assim, indicamos direções para futuras pesquisas.

\section{A ESTRATÉgia ENQUANTO CAMPO DE PESQUISA}

Os estudos sobre estratégia remontam ao artigo de Charles Lindblom, The science of muddling trough, publicado em 1959, que trata sobre o processo de construção de políticas públicas na esfera governamental. A partir daí, as ideias propostas no artigo foram amplamente utilizadas no setor privado e seguem como referência para aqueles que escrevem sobre o processo pelo qual as estratégias são construídas. Embora a abordagem de Lindblom (1959) seja claramente descritiva, o autor defendeu em outro artigo, publicado 20 anos depois, e que tratava sobre a necessidade de se considerar a análise política como um processo social (Lindblom, 1979).

Em 1978, Mintzberg, em seu artigo Patterns in Strategy formation, argumenta que a definição da estratégia clássica, aqui entendida como um plano explícito, desenvolvido conscientemente, é: i) incompleto; ii) necessita considerar como as estratégias são realmente feitas; e iii) o conceito de estratégia deve incluir e ser estendido pela ideia de estratégia como um fluxo de decisões. Mintzberg (1987) utiliza cinco diferentes definições para tentar explicar o conceito de estratégia. Segundo o autor, uma boa tentativa para definir o conceito de estratégia envolveria abordar as definições de estratégia como: um plano, uma manobra/truque ( $p l o y)$, um padrão, um posicionamento e uma perspectiva. O autor aponta que a estratégia também pode ser entendida como um padrão em um fluxo de ações, um comportamento consistente, seja intencional ou não. Nesse contexto, é possível afirmar que uma estratégia somente pode ser reconhecida depois de um conjunto de ações e não previamente a isto. Mintzberg (1987) aponta que se juntássemos estas duas definições poderíamos separar uma estratégia que foi previamente concebida e planejada, isto é estratégia intencionada - estratégia deliberada; e uma estratégia que surgiu como um padrão não previamente estabelecido - estratégia emergente. Destas duas, o que foi concretizado - seja proveniente de uma intenção ou não formaria a estratégia realizada.

Seguindo esta sua tendência anterior, Mintzberg uniu-se a Ahlstrand e Lampel e criou, em 1998, o livro Strategy safári: a guided tour through the wilds of strategic management, o maior trabalho de 
categorização da literatura sobre estratégia empresarial, fruto da revisão de cerca de dois mil itens. Mintzberg (1978) e Chia (2004), dividiram a literatura sobre estratégia em dez escolas de pensamento. As três primeiras escolas enfocam uma natureza prescritiva da formação de estratégia. As seis seguintes enfocam a questão descritiva; e a última escola esforça-se para buscar uma integração entre as demais escolas. Neste período, a área de Estratégia já está desvinculada da área de Organizações e se constitui um campo cientificamente estabelecido, com congressos e journals específicos, organizados em torno da construção de uma ciência "hard" em Administração.

Entretanto, em 1993, Whittington publica What is Strategy - and does it matter?, em que questiona esses valores e propõe a estratégia como uma construção social. Neste livro, Whittington apresenta que as diferentes visões de estratégia poderiam ser divididas em quatro perspectivas genéricas existentes: clássica, evolucionária, processual e sistêmica. Para realizar esta divisão, Whittington (1993) define duas dimensões: uma baseada nos resultados da estratégia e outra no processo em que ela é construída. Na dimensão dos resultados, um lado é representado por uma compreensão de que a estratégia produz - ou busca produzir - a maximização dos lucros; no outro lado admitem-se outros tipos de resultados mais pluralistas. No eixo do processo, um lado aponta um processo deliberado da estratégia e no outro um processo emergente. Com estas dimensões, o referido autor encaixa as perspectivas em cada um dos quatro quadrantes formados pela intersecção das dimensões: i) a perspectiva clássica seria formada no quadrante de um processo deliberado e um resultado focado na maximização dos lucros; ii) a perspectiva evolucionária é formada no encontro de um resultado focado na maximização dos lucros e um processo emergente. Esta perspectiva não confia na capacidade dos estrategistas para agir racionalmente e criar um plano para a maximização dos lucros; iii) a perspectiva processual da estratégia é formada no encontro de um processo emergente com resultados da estratégia mais pluralistas. Nesta visão, o ambiente não garante o melhor lucro para os mais adaptados. Tanto as organizações quanto o ambiente são algo tão confusos que os resultados são absolutamente pluralistas; iv) já a perspectiva sistêmica forma-se no encontro de resultados mais pluralistas e de um processo deliberado.

Segundo Whittington (1993), autores desta perspectiva acreditam na capacidade da organização de planejar o futuro e de agir e influenciar nos seus ambientes, no entanto eles percebem os objetivos e as metas como fenômenos históricos e culturalmente formados. Este tipo de perspectiva desafia a universalidade de um modelo único sobre estratégia: os objetivos da estratégia e os métodos para a criação de estratégia dependem das características sociais dos estrategistas e do contexto social em que estão inseridos. Ou seja, nessa perspectiva, a estratégia é entendida enquanto uma prática social que não está destituída de características sociais, oriundas do contexto e dos indivíduos, envolvidos no processo de realização da estratégia na esfera organizacional.

\subsection{Estratégia enquanto prática}

A abordagem da estratégia enquanto prática começou a ser considerada em meados dos anos 1990. Smircich e Stubbart, por exemplo, indicavam, em 1985, a preocupação com uma perspectiva mais prática da estratégia, em especial uma preocupação com os estrategistas. O artigo "Strategic Management in an Enacted World" chama atenção para o fato de que a relação entre as organizações e seus ambientes era palco de duas abordagens distintas que disputavam a atenção no momento: i) uma abordagem de ambiente objetivo - que enxerga o ambiente como algo concreto, real e passível de ser compreendido e estudado; e ii) uma abordagem de ambiente percebido - que reafirma a realidade do ambiente, mas aponta a incapacidade do estrategista de compreender este ambiente completa e corretamente.

Os autores se preocupam em apontar a necessidade de se incluir uma perspectiva interpretativa do ambiente, considerando que o ambiente é algo socialmente construído, e que a organização e o ambiente são criados conjuntamente, por meio de processos de interação social dos participantes-chave da organização. O objetivo apontado pelos autores não era tentar defender esta vertente ante as anteriores, mas salientar a importância de se considerar esta perspectiva e as consequências que ela traz. Esse trabalho chamava a atenção para a necessidade de estudar como funciona a mente dos estrategistas e como as percepções e construções da realidade são criadas dentro das organizações.

Outro precursor na visão da estratégia enquanto prática é o artigo Corporate Strategy, Organizations, and Subjectivity: A Critique, publicado em 1991 por David Knights e Glenn Morgan. A estratégia corporativa seria um discurso e, para os autores, isto pode ser observado pelo simples fato de que as organizações sempre existiram e nunca precisaram do discurso da estratégia para sobreviver e se desenvolver. A emergência do discurso da estratégia é analisada sob uma perspectiva histórica e relacionada à: i) mudança na relação dono/gerente da organização; ii) ao crescimento e a internacionalização das organizações americanas, e iii) nova complexidade estrutural da companhia - multidivisões e etc. Os discursos seriam reforçados e reproduzidos também por meio do apoio de escolas de administração, consultores, contadores e usuários da estratégia. É importante pontuar que, nesta visão, Knights e Morgan (1991) indicam que a estratégia não se colocaria como um mecanismo para 
criar uma solução para um problema existente, ela criaria a solução na medida em que criou também o problema. No sentido de discurso foucaultiano, a estratégia seria um poder capaz de constituir uma série de efeitos: i) racionalização do sucesso e fracasso dos gerentes; ii) sustento das premissas gerenciais; iii) sentido de segurança pessoal e da organização para os gerentes; iv) sustento de um modelo masculino de gerenciamento; v) demonstração externa da racionalidade gerencial; vi) facilitação e legitimação do exercício de poder; e vii) constituição da subjetividade dos membros da organização (Knights \& Morgan, 1991).

Outro estudo que também indicou uma visão da estratégia como prática social é o artigo de Gioia e Chittipeddi (1991) sobre o processo de mudança em uma universidade americana. Este trabalho avaliou o processo de mudança nesta organização por meio de uma perspectiva da construção de sentidos. Além dos trabalhos mencionados anteriormente, o artigo de David Barry e Michael Elmes, Strategy Retold: Toward a Narrative View of Strategic Discourse contribuiu para o estudo da estratégia enquanto prática, apresentando uma visão da estratégia como narrativa ou estória.

Barry e Elmes (1997) inicialmente atentam para a importância adquirida pelo tema da estratégia e para as diversas correntes de pensamento criadas para analisá-la. Eles sugerem uma nova forma de análise, estudando-a como uma narrativa, como uma estória que é contada dentro e fora da organização. Os autores não se preocupam em debater esta perspectiva perante outras, mas sim defendem que os pesquisadores tenham à mão uma nova lente para observar a estratégia. Segundo os autores, esta perspectiva reconhece a existência de análises anteriores preocupadas em entender a estratégia como componentes de construção de sentido (Weick, 1995). Barry e Elmes (1997) apontam que, independentemente de a estratégia ser considerada planejamento, manobra/truque (ploy), posicionamento, padrão ou perspectiva (Mintzberg, 1987), ela é sempre algo construído para persuadir os outros em certo entendimento, em certas ações. Neste sentido da narrativa, o sucesso de uma estratégia não reside na capacidade de análise, no planejamento de objetivos e nos sistemas de controle, mas na sua compatibilidade com outras histórias organizacionais, na persuasão, ou no caráter inovador das histórias contadas. O trabalho destes autores é interessante não somente porque apresenta a estratégia e o fazer estratégia como uma prática social, no caso de uma narrativa, mas também porque o aprofundamento deste tipo de pesquisa reforça a necessidade uma abordagem mais prática para entender as mudanças das narrativas e o surgimento destas narrativas dentro da organização.

Com o passar do tempo, novos estudos sobre a estratégia como prática começaram a apresentar abordagens com enfoques variados (Whittington, 2006, 2007; Kaplan, 2007; Jarzabkowski \& Seidl, 2008; Raschie \& Chia, 2009; Fenton \& Langley, 2011; Maciel \& Augusto, 2013; para citar alguns). Ainda assim, Whittington continua sendo um dos principais autores a propor esta abordagem diferenciada para a estratégia, visto que que esse autor não ignora a existência da atividade estratégica, mas apenas a observa enquanto uma prática social. $\mathrm{O}$ fato é que, na visão de Whittington (2002), o modernismo imprimiu restrições epistemológicas ao estudo da estratégia sendo preciso superá-las. Por isso, ele sugere que a estratégia seja abordada nos seguintes aspectos: a práxis da estratégia, os praticantes da estratégia e as práticas da estratégia, em outras palavras, o trabalho, os trabalhadores, e as ferramentas/tecnologias da estratégia. Na visão do autor, seria da inter-relação entre esses três aspectos que se realiza, na prática, a estratégia e se produz o seu resultado. Além disso, Whittington (2002) ressalta a relevância dos praticantes das estratégias, (executivos, por exemplo), que permitem que essas possam ser entendidas como uma prática social. Isso ocorreria, pelo fato desses praticantes desenvolverem o trabalho de fazer estratégia (por exemplo, criar um plano ou tomar uma decisão estratégica, em uma visão mais formal), mas necessitando, para tanto, se utilizarem das práticas disponíveis para desempenhar suas atividades (por exemplo, conceitos que aprenderam na escola, conceitos gerais disponíveis no mercado, prática de consultorias, e experiências anteriores).

Uma vez apresentada a estratégia como prática, enquanto um enfoque de pesquisa possível, outros artigos passaram a sedimentar o tema na área acadêmica. Em janeiro de 2003, por exemplo, foi publicada uma edição especial do Journal of Management Studies com o tema de Microestratégia e Fazer Estratégia (strategizing). A introdução, feita pelos editores, Gerry Johnson, Leif Melin e Richard Whittington, traz contribuições para fundamentar esta linha de pesquisa, justificar a sua relevância e apontar oportunidades e desafios para este campo.

Johnson, Melin e Whittington (2003) apontam que a razão de terem organizado uma edição especial, é para enfatizar a importância dos processos e das práticas que constroem as atividades diárias da vida organizacional e que, de alguma maneira, estão associados a resultados ligados a estratégia. A proposta não é, segundo os autores, ignorar ou tentar desprezar contribuições vindas de correntes teóricas com uma abordagem macro para a estratégia, mas sim valorizar os benefícios complementares que uma abordagem micro do assunto traz. Para eles, esta visão micro da estratégia contribuiria também com duas correntes teóricas, a Resource-Based View e o Institucionalismo. A primeira, seria beneficiada porque o valor dos recursos depende da sua utilização e não da sua existência. Assim, esta perspectiva poderia mostrar 
como as atividades são desenvolvidas na prática e como elas podem construir vantagens competitivas sustentadas - o que não pode ser explicado pelas grandes categorias genéricas utilizadas em uma abordagem macro. A Teoria Institucional também poderia se beneficiar da microestratégia. Segundo os autores, isto ocorreria porque esta abordagem exploraria como funciona o processo de negociação que forma as normas e regras de uma organização pelos autores envolvidos. Um estudo neste sentido complementaria a visão de como os indivíduos são capturados dentro destas normas e regras.

Whittington e outros autores se uniram na busca por um maior desenvolvimento deste campo de pesquisas. Como resultado do trabalho e da preocupação destes autores com o tema, foi criada uma comunidade online $\quad$ http://www.strategy-aspractice.org $>$. Este grupo troca experiências e promove fóruns sobre o tema da estratégia enquanto prática. Jarzabkowski e Seidl (2008) ajudaram a organizar a comunidade strategy-as-practice, contribuindo para a abordagem da estratégia enquanto prática social. Esta contribuição agrega, inclusive, novas preocupações de pesquisa sobre o tema. Tais autores, no artigo Strategy as practice: Recursiveness, Adaptation, and PracticesIn-Use, apontam dois aspectos importantes da prática, a recursividade e a adaptação. Para tanto, o artigo se apóia nos conceitos de estruturalismo de Giddens e de habitus de Bourdieu para sustentar a importância da recursividade na constituição das práticas sociais.

Chia (2004) concentra seus esforços em apontar que precisamos estudar a estratégia naprática, e que, para isso, os pesquisadores precisam deixar de fazer representações da prática e resgatar o real sentido de prática - no tempo e espaço em que as ações realmente acontecem e não no tempo e espaço em que a ciência avalia as ações. Chia sustenta em seu artigo que, na verdade, os estrategistas agem nas organizações como desbravadores (buscadores de caminho) e não como navegadores. A visão de estrategistas enquanto navegadores seria uma visão da academia e de consultores que entenderia o trabalho de um estrategista como de alguém que está tentando se localizar dentro de um mapa e que vai traçar um caminho para onde quer chegar. Segundo o autor, esta visão se basearia em uma tradição cognitiva que defende a ideia de que o ser humano constrói um desenho mental de como agir, antes de agir, antes de aplicar algo na prática. Talvez, uma boa ilustração para a visão de estratégia defendida por Chia, seja a frase do poeta espanhol Antônio Machado: "Caminante, no hay camino, se hace camino al andar".

O artigo Taking Strategy Seriously: Responsibility and Reform for an Important Social Practice, de Whittington et al. (2003) destaca a importância da estratégia como prática social e faz uma análise crítica do uso da estratégia. Os referidos autores estudam o caso da Enron e de suas consequências para chamar a atenção para a utilização da estratégia de maneira a manipular informações e realidades conforme determinadas intenções. Os autores abordam, neste caso, o componente de discurso na estratégia e apresentam a relação dos atores envolvidos na construção e na utilização destes discursos de estratégia. Whittington et al. (2003) propõem uma nova agenda que envolve: i) a pesquisa - na comparação com outras disciplinas e na abordagem a temas como poder, interação e mudança; ii) políticas de estratégia regulação e preocupação com a transposição da estratégia para outras esferas; e iii) agenda para praticantes - que envolve uma preocupação das escolas em preparar praticantes mais críticos e conscientes.

Outro aspecto interessante desenvolvido na pesquisa sobre a questão do discurso na estratégia é o proposto por Samra-Fredericks (2004), que defende a necessidade de se estudar a estratégia, sob o ponto de vista da sua construção. Em especial preocupa-se em analisar como a linguagem é utilizada para construir sentido e os caminhos que os participantes utilizam para criar um discurso da estratégia. $\mathrm{O}$ autor aponta que a estratégia é um objeto social que é constituído por meio do discurso e da fala dos membros organizacionais, especialmente daqueles que o autor chama de elites gerenciais - diretores, executivos, CEOs, que participam de atividades onde a estratégia é discutida e que possuem o aval social para discutir a estratégia.

Seidl (2003) utiliza o componente de discurso de maneira um pouco diferente, ao defender a ideia da existência de conceitos gerais de estratégia. Inicialmente, o autor aponta que fazer estratégia pode ser entendido como um processo de seleção e combinação de formas de redução da complexidade organizacional, permitindo que a organização seja tratada tanto cognitivamente quanto praticamente. No entanto, devido ao nível de grande complexidade é praticamente impossível este processo de seleção, que acaba sendo uma seleção cega. Desta maneira, o que realmente é feito é a construção de um modelo simplificado da situação estratégica com base em certas premissas desenhadas para reduzir a ambiguidade.

Pye (2003) utiliza-se da abordagem de Weick (1995) de construção de sentido para analisar brevemente dois casos no mundo da telefonia: Marconi e British Telecom. Pye (2003) chama atenção para as diferentes visões dos atores participantes, em diferentes tempos e situações. A autora aponta também que estas diferentes visões se agregaram em uma construção de sentido única. Pye defende esta abordagem de construção de sentido afirmando que oferece uma análise holística e inclusiva da prática, atentando para questões, tais como poder, tempo e contexto e interrelaciona questões micro com macro. Por fim, Pye defende que tanto a estratégia quanto fazer estratégia ou, ainda, atividades e práticas estratégicas, são todos componentes importantes para ajudar a construir 
sentido para o que está acontecendo dentro das organizações.

Embora seja apropriado pensar sobre os componentes envolvidos na construção do sentido da estratégia empreendida nas organizações, Varyani e Krammer (2010) alertam sobre o fato de que a estratégia não é algo que as organizações possuem, mas algo que as pessoas fazem no interior do contexto organizacional. Isto evidencia que um enfoque de pesquisa oportuno é investigar quem são os estrategistas e quais são os seus papéis, de modo a utilizar as evidências do campo para o reposicionamento do debate sobre o tema.

Um dos recentes estudos empíricos realizados sobre a estratégia como prática foi o realizado por Nordqvist e Melin (2010) no qual abordaram a questão das empresas familiares e seus processos estratégicos. O propósito desse estudo foi compreender os aspectos que caracterizam esse grupo organizacional, no que se refere à busca do entendimento sobre a estratégia enquanto prática social. Como resultado, os autores concluíram que existem modos, motivos e campos (também denominados de arenas) que caracterizam as peculiaridades da estratégia empreendida em empresas familiares. São esses fatores que determinam, por sua vez, os sentidos da estratégia enquanto prática social nessas organizações.

Ademais, Whittington et al. (2006) chamam a atenção para o fato de que a concepção da estratégia como prática não substitui a forma tradicional de se compreender a estratégia, pois esta é apenas mais uma via para se ampliar o entendimento sobre o construto. É por esta dimensão que os referidos autores, reforçam a existência de um papel importante das escolas de negócios no que se refere a fomentar a complementaridade de abordagens envolvidas quanto no trato da temática. Isto porque é no momento do processo de ensino que se pode incorporar a compreensão sobre estratégia sem que, para tanto, sejam marginalizados os aspectos inerentes da estratégica como prática.

\subsection{Um olhar sobre a estratégia como prática no Brasil}

Apesar do número crescente de artigos publicados sobre o tema da estratégia como prática, nota-se que ainda existem muitas oportunidades para crescimento no número de artigos, nas redes de cooperação e nos enfoques pesquisados sobre o assunto no Brasil (Walter \& Augusto, 2011). Entre o período de 1991 e 2002, chama atenção que a produção científica brasileira de estratégia não apresentou nenhum trabalho cuja abordagem fosse à estratégia enquanto prática social (Bertero, Vasconcelos, \& Binder, 2003).

Ainda assim, o início do século XXI já se mostrava como o momento no qual ganhariam espaço, no Brasil, os estudos sobre a estratégia como prática. Vasconcelos (2001), por exemplo, realizou um estudo sobre as diferentes visões de estratégia com base na vivência dos executivos que participam destas atividades dentro da organização. Este trabalho propiciou um agrupamento de diferentes correntes da estratégia, mas não com base em modelos teóricos, e sim se fundamentando na visão dos praticantes da estratégia.

Um ano mais tarde, Vasconcelos (2002), realizou entrevistas com diretores e empresários de 83 empresas de internet com o objetivo de investigar a natureza do processo de formação de estratégia. Este artigo explora a necessidade de não se concentrar especificamente em uma análise objetivista da Estratégia Empresarial, mas sim incorporar uma abordagem construtivista para o tema. De maneira especial, este artigo explora a existência de um componente de isomorfismo estrutural na formação estratégica dentro das organizações observadas. Neste sentido, este artigo retoma alguns princípios da teoria institucional e procura apresentar alguns dos mecanismos indutores de isomorfismo, como colocado pela teoria.

A partir de então, aumentou o volume de estudos que abordaram a influência do contexto social na maneira como as estratégias são realizadas pelos indivíduos nas organizações (Pereira, 2004; Barros \& Oliveira, 2004; Assis \& Afonso Netto, 2004; Pereira \& Agapito, 2005; Pardini, 2005; Canhada \& Bulgacov, 2011; alguns exemplos). Especificamente, os estudos sobre a estratégia como prática, foram intensificados no Brasil a partir do ano de 2005 (Tureta, Rosa, \& Santos, 2006; Santos \& Tureta, 2006; Saraiva, 2007; Oliveira, Canuto, \& Mussi, 2009; Pereira et al., 2010; Josemin, 2011; Tureta \& Lima, 2011; Souza, 2011; Valadão \& Silva, 2012; entre outros). Alguns desses artigos abordam parte da temática sugerida por Whittington. No entanto, a agenda de pesquisa, proposta por Whittington (2002) e pela comunidade de estratégia enquanto prática envolvem diversos temas que não estão sendo pesquisados no contexto nacional. Além disso, as questões metodológicas, necessárias para alcançar a práticas de estratégia, não têm sido suficientemente debatidas.

Por esse motivo, nesta pesquisa, a busca é preencher esta lacuna ao se apoiar metodologicamente no socioconstrucionismo para se aproximar da estratégia na prática. Os passos metodológicos da pesquisa estão descritos a seguir.

\section{ABORDAGEM TEÓRICO-METODOLÓGICA}

A fim de realizarmos uma abordagem metodológica pouco difundida nos estudos sobre estratégia, seja no sentido mais amplo ou delimitada a estratégia enquanto prática social, optamos por 
desenvolver o nosso artigo a partir da abordagem do construcionismo social. As razões que nos levam a fazer essa escolha metodológica surgem de razões variadas, as quais esclarecemos a seguir.

A virada linguística dos anos 1960 questionou a suposta racionalidade individual proposta pelo modelo modernista nas organizações (Gergen \& Thatchenkery, 2006). Os pressupostos filosóficos que levam à discussão de uma epistemologia pós-modernista apoiam-se na linguagem para mostrar que significados são permanentemente construídos e ressignificados (Calas \& Smircich, 1999). Neste sentido, é fundamental buscar quais os significados de cada ação humana. Schwandt (2000) diz não há realidade possível, apenas uma construção dialógica permanente que inclui a ideia de estruturas sociais decorrentes da história e da cultura no caso de um construcionismo "mais fraco".

É exatamente a possibilidade desta "desconstrução", que permite questionar os discursos tidos como naturais. Berger e Luckmann (1985) mostraram como os processos de socialização são responsáveis pela "objetivação" da realidade. Na base da experiência social está a linguagem, que permite, ao mesmo tempo, a construção destas experiências e uma forma de investigação dessa mesma realidade (Cunliffe, 2008). Na visão de Spink e Frezza (1999), a construção social decorre do "tempo longo" que traz os conhecimentos estabelecidos em campos de saber, instituições, "estruturas" sociais objetivadas ao longo da História. Além disso, cada pessoa tem sua trajetória, seu "tempo vivido", num dado contexto, numa dada cultura, referenciais afetivos e cognitivos que permitem a construção de um self, mas esse self está permanente imerso em múltiplas interações face a face, descrito como "tempo curto".

Como as pessoas, as organizações se constroem no tempo longo, no tempo vivido e no tempo curto das interações que, incessantemente, criam e recriam sentidos. A linguagem não revela, ela propriamente constrói o mundo (Gergen \& Thatchenkery, 2006). Esta pesquisa está apoiada nessa abordagem pósestruturalista para a investigação da estratégia enquanto prática social. No estudo da estratégia, enquanto prática, tradicionalmente, tem sido utilizado estudos de caso e etnografia (Albino et al., 2010; Barbosa, Canetginer, \& Peris-bonet, 2010; Souza, 2011; para citar alguns). No entanto, apesar de as discussões em torno da estratégia considerarem exatamente que ela resulta de uma construção social, o uso do construcionismo social como recurso metodológico não tem sido largamente utilizado.

Balogun, Huff e Johnson (2003), por exemplo, levantam a discussão sobre a metodologia para se estudar strategizing ou fazer estratégia. Eles partem do dilema de se querer observar o processo na prática, por meio de estudos de caso ou etnografia e a consequência de se ficar restrito e limitado a uma baixa capilaridade em um ambiente de grande complexidade e diversidade. Assim, os autores sugerem que a pesquisa seja feita com base em dados coletados por observação, entrevistas e documentação. Os autores apontam a necessidade de se incluir o praticante como produtor da pesquisa e não apenas como fonte de informação. Nesta pesquisa, a abordagem não se restringe a um processo interpretativo dos pesquisadores e considera que os praticantes investigados foram o processo de produção de conhecimento.

Para a coleta de dados, foram utilizadas entrevistas semiestruturadas considerando, para tanto, que o referencial socioconstrucionista seria o recurso utilizado para análise dos dados (Berger \& Luckmann, 1985; Schawandt, 1995; Spink, 1999; Cunliffe, 2008). Os procedimentos realizados que dão visibilidade a esse processo são apresentados a seguir.

\subsection{A pesquisa de campo}

Entrevistamos um grupo de executivos/donos de empresas que atuam com a estratégia no seu dia a dia. $\mathrm{O}$ objetivo era conseguir reunir um conjunto diversificado de participantes. O critério principal foi buscar pessoas que estivessem envolvidas com a estratégia de suas organizações, isto conduziu essencialmente para pessoas em posições hierárquicas de diretores, presidentes, ou sócios, com responsabilidade direta sobre o direcionamento de suas empresas. Neste sentido, trata-se de uma amostra intencionalmente construída.

O conjunto de participantes da pesquisa foi formado por 23 pessoas sendo três mulheres e 20 homens. A idade destas pessoas variou entre 27 e 62 anos, com maior concentração para pessoas na faixa dos 50 aos 60 anos de idade. De todos os 23 entrevistados, apenas um não possuía formação superior. Oito dos entrevistados possuíam cursos de pós-graduação em nível lato sensu, com exceção de um entrevistado que iniciou um mestrado, embora ainda não tivesse apresentado sua defesa de dissertação. Além disso, em sua grande maioria, a formação dos entrevistados é em engenharia, 13 pessoas, seguida por administradores no total de quatro representantes.

O tempo de atuação profissional dos entrevistados nas respectivas organizações em que atuam variou de dois anos a 33 anos de empresa. O maior grupo, representado por nove integrantes, é o de entrevistados que estão entre dois e dez anos de atuação. O segundo grupo inclui sete participantes, e apresenta aqueles que estão na empresa entre 11 e 20 anos.

Oito dos entrevistados são donos ou sócios dos negócios. Um segundo grupo de 12 pessoas é daqueles que são executivos contratados pelas organizações. Por fim, temos também o caso de dois entrevistados que são filhos do dono das empresas. Em ambos os casos, tanto os filhos quanto os pais foram entrevistados. 
Excluindo o grupo de sócios/donos das empresas, temos seis diretores, quatro gerentes e quatro presidentes ou vice-presidentes. Por motivos de confidencialidade acordado com os entrevistados, estes não serão identificados, bem como os nomes de suas empresas não serão apresentadas.

Entre as organizações, 14 delas são nacionais, dentre as quais duas apresentam filiais fora do Brasil. Além disso, há também cinco empresas filiais de multinacionais estrangeiras. Entre os entrevistados, 17 fazem parte de grupos nacionais e cinco de grupos multinacionais estrangeiros. O capital da maioria das empresas é fechado. Apenas quatro delas apresentam capital aberto, seja em bolsas de valores nacionais ou internacionais, no caso das organizações multinacionais. Em relação ao setor de atuação das empresas, o grupo estudado compõe-se de oito organizações inseridas no setor industrial e 11 organizações no setor de serviços.

\subsection{Procedimentos para coleta e análise de dados}

Nesta pesquisa, utilizamos uma abordagem de entrevista semiestruturada para a coleta de dados. Antes do início de cada entrevista, buscou-se identificar o perfil do entrevistado, a saber: idade, formação, tempo de empresa, posição, tempo de existência da empresa e tamanho da empresa. Após a coleta dessas informações, começava-se a conversa a partir de questões, tais como qual o sentido da palavra estratégia para você? Como a estratégia é utilizada na sua empresa? Quem são os responsáveis? Logo com o início da entrevista, o entrevistado passava a direcionar os caminhos da entrevista e o entrevistador intervinha apenas para alguns esclarecimentos ou para colocar novos assuntos quando o entrevistado encerrava suas exposições. Algumas vezes, a simples menção do tema estratégia já propiciava que o entrevistado começasse a falar, dispensando a intervenção do entrevistador, a não ser para esclarecer ou explorar pontos de interesse que surgiam.

Todas as entrevistas foram gravadas para posterior transcrição. Uma vez transcritos os relatos dos entrevistados, todo o material foi categorizado em temas comuns, a saber: definições de estratégia; explicações do processo de criação da estratégia; influência do ambiente; quem faz estratégia; quem influencia estratégia; consenso e construção de sentido; valorização social da estratégia; dia a dia e estratégia; cultura organizacional; metáforas utilizadas; sentidos para a palavra; dentre outros. Esta abordagem permitiu levantar informações de diferentes entrevistados, bem como realizar uma visão inicial mais ampla da situação possibilitando comparação de contextos. Nesse sentido, apontam-se duas considerações: (i) Como apontado por Balogun, Huff e Johnson (2003), é necessário considerar uma visão mais abrangente e flexível, que pede outros métodos de pesquisa. Dos critérios apontados pelos autores, a nossa abordagem incorpora: a amplitude, a efetividade do tempo e as múltiplas questões da realidade organizacional.

$\mathrm{Na}$ nossa visão, o compromisso dos participantes também foi conquistado pelo objeto de pesquisa e o interesse que ele provoca dentro da organização. Ainda que questionada como instrumento de coleta de dados, as entrevistas têm sido, ao longo de muitas décadas de pesquisa qualitativa, um instrumento central para a coleta de dados; (ii) $\mathrm{O}$ processo de construção de sentido (Weick, 1995) envolve a associação entre ações e estruturas que explicam estas ações. Uma vez que o interesse está nos sentidos atribuídos à questão da estratégia, é primordial não apenas a ação, mas esta relação entre a ação e as estruturas, isto é a unidade de sentido que as explica. A entrevista permite e envolve o praticante na atribuição de sentidos para as suas ações, por ele próprio, embora claramente exista a participação do entrevistador. Aqui, cabe resgatar a proposição de Wittengstein apontada por Spink (1999) de que as pessoas se reconhecem nos atos de fala, e, de maneira especial, o trecho de Wallas, utilizado por Weick (1995) para conduzir o seu livro: How can I know what I think till I see what I say? São apresentados, a seguir, parte dos resultados obtidos com a análise dos repertórios linguísticos dos entrevistados.

\section{RESULTADOS DA PESQUISA EMPÍRICA}

A partir da análise dos dados, cujas categorias emergem dos repertórios linguísticos dos entrevistados, ou seja, dos dados coletados em campo, destacam-se três resultados: os sentidos atribuídos à palavra estratégia; algumas questões relativas à construção social do sentido da estratégia; e a valorização social da estratégia nas organizações.

\subsection{Sentidos em que o termo estratégia é utilizado}

Um primeiro aspecto que desperta atenção na análise das entrevistas é a utilização do termo estratégia, do termo adjetivado estratégico, ou do advérbio estrategicamente. O termo é usado pelos entrevistados com sentidos diversos e, especialmente, como atributo para vários substantivos ou ações realizadas. A julgar pelas recorrentes utilizações, parece que esse termo incorpora muitos sentidos e pode ser empregado para diversos objetos. Transparece a ideia de que vários aspectos de uma organização podem ou não ter o adjetivo estratégico associado e que as mais diversas ações podem ser realizadas de "maneira estratégica". Para facilitar o entendimento, a figura a seguir apresenta diferentes usos da palavra pelos entrevistados. 


\begin{tabular}{|c|c|}
\hline \multicolumn{2}{|r|}{ SENTIDOS ENCONTRADOS PARA ESTRATÉGIA } \\
\hline Principais sentidos & $\begin{array}{l}\text { - Um plano, uma ação para se alcançar algum objetivo. } \\
\text { - Algo que garante o funcionamento de um projeto. } \\
\text { - Ação para resolver determinado problema. } \\
\text { - Forma de atuar em uma negociação ou de abordar um cliente. } \\
\text { - Forma de olhar o mercado. } \\
\text { - Atributo para ação da organização ou de seus executivos. } \\
\text { - Atributo de como a empresa pode se estruturar. } \\
\text { - Ações integradas do governo. } \\
\text { - Forma de uma organização se questionar. } \\
\text { - Forma da empresa de se posicionar. } \\
\text { - Forma de prever o futuro. } \\
\text { - Forma de apresentar um produto. }\end{array}$ \\
\hline $\begin{array}{l}\text { Alguns outros usos de } \\
\text { estratégia, como adjetivo: }\end{array}$ & $\begin{array}{l}\text { Questão estratégica; visão estratégica; pensamento estratégico; crítica } \\
\text { estratégica; raciocínio estratégico; planejamento estratégico; pano de fundo } \\
\text { estratégico; linhas estratégicas; objetivos estratégicos permanentes; dimensões } \\
\text { estratégicas; questionamento estratégico; direcionamento estratégico; processo } \\
\text { de reflexão estratégica; decisão estratégica; direção estratégica e postura } \\
\text { estratégica }\end{array}$ \\
\hline
\end{tabular}

Figura 1 - Breve resumo dos sentidos em que o termo estratégia é utilizado

Fonte: Elaborado pelos autores.

Os diferentes usos da palavra mostram que, embora o termo estratégia esteja muito presente no dia a dia das pessoas que trabalham nas organizações, ele apresenta um conceito que não é claro e único para todos. Muitas vezes, a própria pessoa usa a palavra em sentidos distintos, empregando-a em situações diversas. Encontramos o emprego da palavra em um conceito geral, de algo que a organização possui. Mas ela também é empregada em sentidos específicos para explicar um plano para alcançar determinado objetivo, ou uma ideia para conseguir que algo seja feito de maneira diferente, ou uma solução para um problema, ou para se defender de uma situação complicada. O termo também é aplicado para denotar uma forma bemfeita e criativa de fazer alguma tarefa, ou como artimanhas de uma negociação.

Podemos resgatar que esta amplitude de conceitos do termo estratégia já foi apontada na literatura acadêmica, por exemplo, com os 5Ps de Mintzberg (1987). O autor apontava que para se criar um conceito pleno de estratégia seria necessário incorporar, de maneira integrada, diversos conceitos: um plano, uma manobra (ploy), um padrão, um posicionamento, e uma perspectiva.

De maneira geral, estas cinco perspectivas ajudam a categorizar alguns dos sentidos em que os entrevistados empregaram o termo estratégia. No entanto, na nossa pesquisa, foi possível encontrar alguns sentidos mais particulares, como a estratégia como certa antecipação do futuro e, em especial, como uma categorização para ações realizadas na empresa ou por uma pessoa. Este emprego, em particular, é bastante interessante. Parece que a palavra hoje em dia é utilizada para diferenciar algo realizado de maneira inteligente, de algo realizado de maneira simples, trivial.

\subsection{Construção social do sentido da estratégia}

Weick (1995) aponta que a construção de sentido é algo retrospectivo que procura explicar a realidade, e os fatos ocorridos, com base em crenças e valores existentes, buscando assim dar sentido para aquilo que aconteceu. Para o autor, o processo de criação de sentido não é apenas interpretativo da realidade, mas é ativo e constrói a realidade em que está inserido. Os trechos abaixo apontam para a questão da construção social da estratégia. Os membros da organização envolvidos no processo procuram juntos compreender a realidade em que estão inseridos, de maneira conjunta eles tentam entender o que está acontecendo e assim chegam a um acordo sobre a realidade, eles criam a realidade social em que estão inseridos. Vejamos o que os entrevistados disseram quando questionados sobre o que vem a sua cabeça 
quando se fala em estratégia ou quando questionado sobre "o que é estratégia":

Quando você fala em estratégia
éééé....quando você fala em estratégia, eu
penso na na, eu penso nana, na
fundamentação das, das, das, na
fundamentação das nossas ideias éée e no
planejamento de como transformar essas
ideias em, em, em prática em projeto, em
negócio em ações. (Entrevistado11).

É difícil né, é uma daquelas palavras assim com pequenas definições conceituais e tal, mas enfim, mas acho que no dia a dia a estratégia, estratégia pra mim é o planejamento da ação, é a... acho que antes da estratégia vem toda uma parte de conceituação de filosofia, de atuação, de política, de linhas gerais e tal né isso é todo um bloco de pensamentos e ideias que tem que fazer parte de um negócio e de um projeto. Desse bloco, desse bloco de ideias, de pré-condições enfim, até a ação, tem uma discussão de como isso deve acontecer né que (Entrevistado 01).

Então é normalmente as ideias, as ideias de um plano mais estratégico elas sempre são debatidas, elas sempre nascem da cabeça de um dos sócios ou de alguém dentro da, dentro da, da nossa, da nossa estrutura do nosso trabalho e essa ideia na verdade ela é, ela é, ela é jogada formalmente num fórum que a gente tem de terça-feira à tarde, ela é colocada prum debate entre os cinco sócios né pra ver si, si se essa ideia alcança, alcança eco e normalmente a gente, como são ideias que mexem com questões estruturais e muitas são questões estratégicas grandes, a gente tenta buscar até um consenso de que é importante pensar sobre aquilo, se aprofunda e é transformar aquilo numa estratégia em um projeto ou em alguma coisa, alguma coisa desse tipo (Entrevistado 13).

\subsection{Valorização social da estratégia}

Destaca-se a seguir, alguns comentários dos nossos entrevistados que denotam a valorização social da estratégia. De maneira geral, são comentários que chamaram a atenção por mostrarem, ou, pelo menos, parecerem mostrar, uma grande preocupação dos entrevistados em se mostrarem grandes estrategistas, ou grandes conhecedores da estratégia. Neste trecho, o entrevistado parece se desculpar por usar uma definição da estratégia tão básica. O entrevistado estava incomodado de dar uma explicação sobre estratégia que saísse do lugar comum, na sua visão:

Acho que quando você não sabe para onde você quer ir. Não tem a menor chance de você chegar em algum lugar. Este é o primeiro ponto, básico, e na verdade, é realmente muito básico (Entrevistado 01).

Os três trechos abaixo mostram entrevistados que pareciam se preocupar em associar-se como responsáveis pela estratégia ou como pessoas capazes no tema da estratégia:

Eu sou fã de coisa estratégica. Eu adoro, gosto de política, gosto de visão, acho, não, o próprio [consultor] falou: você, de todos aqui, é que consegue fazer melhor a imagem do raciocínio estratégico. Até acho que por ter saído da empresa, a gente já está levando ela muito para uma crítica (Entrevistado 08).

Mas eu considero, quando eu converso com o acionista, eu considero que eu, que esse é o meu maior job, garantir, como se eu fosse assim, o Ouvidor da Estratégia. Tenho que garantir que essa estratégia seja implementada. Se alguém perguntar qual o seu principal job? Eu vou dizer que é esse. Pessoas, processos, tem tudo isso. Mas eu acho que passa muito por você ter alguém que diga: vou cuidar que a estratégia seja cumprida, porque o dia a dia, não é fácil (Entrevistado 05).

Estes trechos nos mostram a existência desta Valorização Social da Estratégia também na classe dos executivos. Estes depoimentos reforçam a percepção de quanto o tema da estratégia se tornou reconhecido como algo nobre em nossa sociedade.

\section{DISCUSSÃO DOS RESULTADOS}

Ao sugerirmos o construcionismo social como uma abordagem metodológica útil na compreensão da estratégia enquanto uma prática social, utilizamos a lente teórica do construcionismo e da estratégia como prática social para interpretar os relatos de 23 executivos/donos de empresas que atuam com estratégia em seu cotidiano de trabalho. Ao interpretarmos os repertórios linguísticos dos entrevistados, sob a lente teórica de nosso estudo, percebemos que existe uma diversidade de entendimentos para os temas "o que é estratégia" e "como a estratégia é criada", no dia a dia da tomada de decisão organizacional.

Por um lado, esse achado de pesquisa nos permite compreender que o estudo empírico da estratégia como prática social, também abre uma boa oportunidade para se discutir a estratégia na prática (EP). Embora não tenha sido o objetivo deste artigo, entendemos que o enfoque sobre como ocorre à formulação e execução da estratégia, em contexto organizacional, pode gerar contribuições importantes para se avançar em compreensões menos diversificadas 
sobre o que vem a ser a estratégia, e como ela é criada pelos agentes tomadores de decisão nas organizações. Nesse sentido, embora o endereçamento de pesquisa recaia sobre um tipo de interesse, diferente do que foi desenvolvido nesse artigo, entendemos que a abordagem construcionista pode servir como uma abordagem metodológica útil para os estudos no campo de estratégia, seja sobre o olhar da estratégia como prática, seja pela via da estratégia na prática.

As razões que nos levam a esse entendimento decorrem de motivos variados, ao mesmo tempo em que trazem à tona a principal lacuna de pesquisa endereçada nesse artigo. Primeiro, embora os estudos sobre a estratégia como prática social sejam um tema relativamente recente no campo (Whittington et al., 2003; 2006; Whittington, 2007), esse tema catalisou o interesse de pesquisadores da área e, desde então, se fortaleceram os esforços de pesquisa sobre o assunto. No entanto, notamos que, embora os estudos sobre a estratégia como prática tivessem se fortalecido no campo da administração, os tipos de pesquisas realizadas basicamente se delimitavam a abordagens teóricas e ou empíricas para validação dos preceitos teóricos e/ou desenvolvimento da teoria sobre estratégia como prática (Albino et al., 2010; Barbosa et al., 2010; Fenton \& Langley, 2011; Josemin, 2011; alguns exemplos). Ante a essa situação, pareceu-nos razoável propor a utilização do construcionismo social - uma abordagem metodológica ainda pouco explorada nos estudos de estratégia - como uma tentativa de conhecer novos insights para discussão da estratégia como prática. Ou seja, a principal lacuna de pesquisa endereçada em nosso estudo se constitui do interesse em ampliar o debate sobre a estratégia como prática, tendo como base a utilização da abordagem metodológica do construcionismo social para a condução de estudos empíricos sobre o tema.

Ao utilizarmos a abordagem do construcionismo social na compreensão da estratégia enquanto uma prática social, alguns insights de pesquisa podem ser focalizados para atingir o objetivo de melhor entendimento do assunto em questão: a práxis, os praticantes, ou as práticas da estratégia (Whittington, 2002). Embora, nos resultados de nossa pesquisa, apareçam alguns aspectos da práxis e das práticas da estratégia, o caminho escolhido em nosso estudo foi de se concentrar, em especial, nos praticantes da estratégia. Nosso foco foi explorar o entendimento e a importância que estes praticantes atribuem à estratégia. Isto envolveu entender tanto o dia-a-dia por onde as estratégias são construídas, quanto as definições e a importância que estes praticantes atribuem à estratégia. Consideramos que estas definições são também explicações, sentidos, que os nossos praticantes atribuem às atividades - relacionadas à estratégia - que eles desenvolvem no dia-a-dia de sua organização. Como uma prática social, procuramos destacar também o entorno, o contexto social onde estão inseridas estas definições. Como resultado destas análises, duas ideias despontaram com maior destaque dentro do trabalho e foram alvos de nosso interesse: i) a grande variedade de entendimentos sobre a estratégia; e ii) a questão da importância atribuída à estratégia.

As definições apresentadas para estratégia variam desde plano até perspectiva, padrão ou posição. No entanto, incluem entendimentos distintos como vontade de mudança ou fundamentação para as ideias. O processo de criação das estratégias também varia muito, no entendimento dos entrevistados. Alguns remetem a processos formais longos e complexos e outros a simples reuniões de decisão. Alguns apontam que a estratégia é resultado de uma análise realizada pelos estrategistas e outros apontam que a estratégia é uma reação ao ambiente, ou resultado de um processo de tentativa e erro. Os entrevistados também apresentam visões diferentes sobre quem são os envolvidos no processo de criação da estratégia, para alguns a cúpula define e para outros toda a organização cria a estratégia.

Diante destas distintas visões, exploramos alguns aspectos que podem influenciar diferenças tanto no resultado das estratégias quanto do entendimento delas, inclusive porque os resultados alteram o entendimento da estratégia (Weick, 1995). A apresentação dos resultados da pesquisa mostrou elementos que influenciam a estratégia, tais como: i) história pessoal e experiências anteriores dos membros da organização; ii) relações com a academia; iii) gosto pessoal; iv) cultura da organização; v) o próprio dia a dia das organizações. Esta lista certamente não é extensiva e nem conclusiva e um estudo mais detalhado deste fenômeno pode produzir resultados muito interessantes.

Este aspecto, de diferentes conceitos para a estratégia, já foi percebido pela academia (Mintzberg, 1987), mas precisa também ser alvo de preocupação dos praticantes da estratégia. Para os praticantes, é útil compreender que os conceitos do que é e de como fazer estratégia são diversos e que tanto entre organizações como dentro da mesma organização alguns membros entendem conceitos de maneira diferente. Assim, pode ser necessário um processo de esclarecimento, ou de acordo, sobre o que se está falando.

De qualquer maneira, ainda que os nossos resultados de pesquisa apresentem diferentes usos para a palavra estratégia, fica muito clara a visão geral dos entrevistados de que estratégia é algo muito importante, fundamental. No entanto, isto nos remete à questão colocada por Knights e Morgan (1991), se a estratégia é tão importante: "Eu acho fundamental, não consigo imaginar uma organização de sucesso sem uma estratégia" (Entrevistado 23), porque então é um tema que surgiu apenas na última metade do século XX, já que as organizações existem há bem mais tempo? Alguns poderiam responder que é uma nova etapa dentro das organizações, uma evolução do que era feito 
antes, algo que surge com uma maior profissionalização das empresas. Knights e Morgan (1991) respondem a esta pergunta de maneira um pouco diferente. Segundo eles, a estratégia é um discurso que está associado a uma necessidade de as organizações se legitimarem e gerarem segurança para a empresa internamente, nas diversas divisões, países e externamente nos mercados financeiros e acionistas. Assim, para os autores, o surgimento da estratégia está associado aos seguintes aspectos: i) à mudança na relação donos/gestores da organização; ii) ao crescimento e internacionalização dos EUA, e iii) à nova complexidade estrutural da companhia multidivisões. Na nossa visão, esta resposta de Knights e Morgan (1991) parece atender à questão da grande proliferação da estratégia nos últimos anos. No entanto, assumi-la como explicação para o fenômeno, nos coloca uma dúvida adicional: Por que a estratégia tem tanta importância em organizações que não são multinacionais e não são de capital aberto, como grande parte de nossos entrevistados? A explicação de Knights e Morgan (1991) não incorpora esta problemática, da importância da estratégia em pequenas e médias empresas gerenciadas pelo dono. Assim, nessa seção de discussão dos resultados e insights de nossa pesquisa, lançamos, a seguir, três proposições para esta questão, as quais não são necessariamente excludentes, e que até podem ser complementares.

Primeiro, os resultados de nossa pesquisa nos levam a entender que a importância da estratégia em organizações menores está associada a um fenômeno social de valorização da estratégia. Em parte, é reflexo da valorização que a academia, o corpo gerencial e a sociedade em geral atribuem ao tema da estratégia. Assim, os membros de pequenas organizações, inseridos neste meio, cursando estas faculdades, lendo as revistas de administração, são influenciados por isto e se sentem impelidos a falar e se preocupar com a estratégia. A estratégia entra, deste modo, como um conteúdo para gerar sentido para aquilo que eles estão realizando dentro de suas organizações;

Segundo, a palavra estratégia, de tempos em tempos, adquire um sentido diferente, como decorrência desta valorização social. Como colocamos anteriormente, a palavra parece ser sinônimo de bom gerenciamento, ou de agir com inteligência dentro da organização. Assim, a grande preocupação com a questão da estratégia estaria associada a um desejo dos membros de demonstrar que atuam como bons gerentes/empresários dentro das suas organizações.

Terceiro, sugerimos uma linha de interpretação que escapa ligeiramente da explicação de Knights e Morgan (1991) e se associa à questão da Construção de Sentido. Segundo Weick (1995), a necessidade de se dar sentido àquilo que está acontecendo e para as ações que se está realizando, é uma característica do ser humano. Desta maneira, podemos supor que este processo de construção de sentido para as ações que estão sendo feitas dentro da organização sempre existiu. A estratégia seria algo que legitimaria, criaria um espaço e estimularia este processo de construção de sentido, e o grande crescimento da estratégia, também nestas organizações, estaria associado a isto.

Feitas essas proposições e considerando os resultados obtidos com a realização desta pesquisa, endereçamos, a seguir, as conclusões deste estudo, bem como uma agenda de pesquisa para futuros estudos sobre o tema da estratégia enquanto uma prática social.

\section{CONSIDERAÇÕES FINAIS}

Desenvolvemos este artigo para propor o construcionismo social, enquanto uma abordagem metodológica útil, para o estudo da estratégia como prática. Por esse lente metodológica, estabelecemos, como objetivo de nossa pesquisa, investigar como praticantes da estratégia constroem o entendimento sobre o que é estratégia, sobre como ela é criada nas organizações, e sobre quem são os envolvidos nesta criação. Isso nos fez sistematizar o conhecimento sobre o tema do construcionismo social e da estratégia como prática, o que nos deu condições para interpretar os repertórios linguísticos dos 23 executivos/donos de empresas entrevistados em nossa pesquisa de campo. Retomados esses esclarecimentos, indicamos, a seguir, as principais conclusões obtidas com a realização desta pesquisa.

\subsection{Contribuições para a teoria sobre estratégica como prática social}

Esta pesquisa traz duas principais contribuições para a teoria sobre estratégica como prática social. Em primeiro lugar, a pesquisa chama a atenção para um tema de destaque da área da estratégia, o que poderá estimular o interesse de outros pesquisadores que se envolvam com o assuntos relativos a estratégia como prática. Nesse sentido, o nosso artigo não só promove o estímulo para se avançar nas pesquisas sobre o tema, mas propõe, sobretudo, uma abordagem metodológica alternativa - entenda-se o construcionismo social - para o desenvolvimento de futuros estudos, o que constitui a segunda contribuição teórica de nossa pesquisa.

Especificamente, ao lançarmos mão de uma abordagem metodológica ainda pouco explorada nos estudos sobre estratégia, buscamos favorecer o entendimento da estratégia como prática, a partir de bases metodológicas renovadas. Contribuímos, dessa maneira, na articulação de um repertório metodológica ainda pouco explorada na área, demonstrando de que maneira ele pode ser constituído e utilizado nos estudos da área de estratégia. Isto porque, em nossa fundamentação teórico-metodológica, trabalhamos, de modo abrangente, os preceitos teóricos que delimitam a 
abordagem do construcionismo social. Pensamos que essa perspectiva integrada poderá ajudar no desenvolvimento de estudos futuros que, por meio de abordagens metodológicas diferenciadas, resguardem o potencial de atingir novos avanços para o debate sobre a estratégia como prática.

\subsection{Contribuições para a prática da pesquisa em estratégia}

Quanto à prática da pesquisa em estratégia, pensamos que este artigo traz três contribuições principais. Em primeiro lugar, ele chama a atenção para os múltiplos elementos envolvidos na abordagem metodológica do construcionismo social, revelando tratar-se de uma estratégia metodológica legitimada nas ciências humanas e que possui efetivo potencial de contribuições para os estudos empíricos da estratégia como prática social.

Em segundo lugar, é possível concluir que a valorização social da palavra estratégia foi um fator decisivo para sua difusão nas falas dos praticantes da estratégia, especialmente entre os atuantes em pequenas empresas, pois o uso da palavra estratégia os legitimou, enquanto membros de uma organização, a demonstrarem que atuam como bons gestores e dão sentido a ações que sempre existiram no espaço organizacional. Nesse sentido, esta pesquisa ressalta o papel da ação individual na construção do processo da estratégia como prática e, desse modo, evidencia a centralidade do indivíduo tomador de decisão, em relação ao modo como percebe a necessidade de mudança e formula suas ações no âmbito organizacional. Este entendimento contribui para que as organizações se atentem para o fato de que a estratégia como prática, não constitui como um recurso imposto no âmbito estratégico apenas por meio de uma imposição da alta gerência, pois o seu êxito reside, preliminarmente, na forma como os indivíduos conseguem perceber a necessidade de mudanças e, assim, formular e engajar os grupos em prol de ações coletivas. Esse alerta pode ser útil tanto para as organizações quanto para os gestores interessados em reforçar as diretrizes estratégicas dos sistemas corporativos e empresariais, com vistas a disseminação de uma prática mais compatível com o entendimento de ser a estratégia uma prática social, mais do que uma prática meramente institucionalizada.

Vale esclarecer que, neste artigo, não procuramos propor uma definição geral para o que vem a ser estratégia em contexto organizacional. Apenas indicamos - por meio de um estudo empírico interpretado pela abordagem do construcionismo social - direções para se pensar a estratégia, em seu sentido mais amplo, a partir dos repertórios linguísticos identificados nas falas dos participantes de nosso estudo. Além disso, também esclarecemos que o termo "valorização da estratégia", utilizado em nosso estudo, foi utilizado como sinônimo para a ideia de "menção" a estratégia pelos participantes nossa pesquisa. Isso requer entender que o termo "valorização" não foi utilizado como um construto teórico de nossa pesquisa teórica-empírica. Foi apenas utilizada como sinônimo de algo - no caso, o termo estratégia - que é de uso rotineiro pelos repertórios linguísticos dos participantes de nossa pesquisa de campo.

Em terceiro lugar, entendemos que uma das maiores contribuições desse artigo foi propor e utilizar a perspectiva metodológica do construcionismo social, enquanto uma abordagem oportuna para se investigar a construção de sentidos em estratégia, sendo essa uma prática social. Por essa razão, o nosso estudo se constituiu, muito mais, como um amplo quadro que emite sinais sobre caminhos alternativos para se pensar e discutir a estratégica enquanto prática, do que propriamente um emissor de avanços teóricos para a discussão sobre o tema. Contudo, ao desenvolvermos uma pesquisa empírica diversificada, aportada por uma base histórica referencial do campo da estratégia, pudemos compreender que, ao utilizarmos a abordagem do construcionismo social, novas estratégias de pesquisa podem se abrir ao difundido debate sobre a estratégia nas ciências administrativas. Contudo, vale ressaltar, tal como demonstrou os resultados de nossa pesquisa, que a estratégia como prática social é um fenômeno complexo e que gera diversas interpretações sobre o seu significado. Isso nos leva a reafirmar que o estudo da estratégia como prática, mesmo se valendo da abordagem metodológica do construcionismo social, ainda é um fenômeno que não admite compreensões e ações simplistas por parte dos gestores ou acadêmicos que se debrucem sobre esse assunto no cotidiano de suas vidas.

\subsection{Agenda para futuras pesquisas}

Reconhecemos que o nosso trabalho apresentou uma visão geral sobre a questão da estratégia enquanto prática, mas deixou de lado o estudo na prática da arte de fazer estratégia, isto é, de observar o processo na prática dentro das organizações. Além disso, a nossa pesquisa também tratou de uma grande diversidade de temas, acarretando na impossibilidade de alguns assuntos serem abordados com a devida profundidade. Por esse motivo, sugerimos algumas direções para estudos futuros, os quais poderão suprir as lacunas de pesquisas não endereçadas neste artigo.

Primeiro, estudos que façam a interseção de tipologias em relação à teoria de Mintzberg (conceito de estratégia) ante às visões estratégicas de Whittington, para que seja possível caracterizar as ações da estratégia como prática, a partir de uma abordagem teórico-empírica. Em segundo lugar, estudos que investiguem se as diferenças entre as características profissionais dos entrevistados (exemplos: tipos de ocupação; tempo de experiência 
profissional; área de atuação) impactam o modo como eles atribuem sentidos à estratégia que empreendem no ambiente de trabalho. Em terceiro lugar, pesquisas que visem, a partir da abordagem do construcionismo social, desenvolver novas investigações empíricas para o entendimento da estratégia como prática social, o que fortalecerá o potencial dessa abordagem para os estudos sobre o tema. E, em quarto lugar, pesquisas futuras que se aprofundem no estudo da arte de se fazer estratégia na prática, pois, entendemos que essa arte na prática reflete, em boa medida, a frase do poeta espanhol Antônio Machado: "Caminante, no hay camino, se hace camino al andar".

Registramos, finalmente, que os estudos futuros sobre a estratégia como prática que se valham da abordagem metodológica do construcionismo social, serão úteis não somente para iluminar o fenômeno em si, mas também para revelar como os indivíduos tomadores de decisão, concebem a prática da estratégia em contexto organizacional, bem como suas implicações para o entendimento da construção social dessa prática nas organizações. Isso nos leva a desejar, portanto, que este artigo incentive outros pesquisadores a explorar as lacunas teóricas e metodológicas sobre o tema da estratégia como prática e que, assim, possam igualmente contribuir para o desenvolvimento do conhecimento sobre o assunto.

\section{REFERÊNCIAS}

Albino, J., Gonçalves, C. A., Carrieri, A., Muniz, R. (2010) Estratégia como prática: uma proposta de síntese. Revista Portuguesa e Brasileira de Gestão, 9(1-2), 1-14.

Assis, S., Affonso Netto, A. (2004) A interpretação dos dirigentes das empresas incubadas brasileiras sobre a avaliação dos recursos da cadeia de valor e a influência dos fatores ambientais na formulação das estratégias empresariais. Anais... EnAnpad Encontro da Associação Nacional de PósGraduação e Pesquisa em Administração, 28, 2004, Curitiba - PR.

Balogun, J., Huff, A., Jonhson, P. (2003) Three responses to methodological challenges of studying strategizing. Journal of Management Review, 40(1), 197-224.

Barbosa, R. A., Canet-Giner, M. T., Peris-Bonet, F. J. (2010) How middler managers contribute to strategy formation process: connection of strategy processes and strategy practices. Revista de Administração de Empresas, 50(4), 358-370.
Barros, L., Oliveira, L. (2004) Planejamento estratégico empresarial vinculado ao planejamento pessoal dos sócios: estudo de caso na empresa mundo animal pet center. Anais... EnAnpad Encontro da Associação Nacional de PósGraduação e Pesquisa em Administração, 28, 2004, Curitiba - PR.

Barry, D., Elmes, M. (1997) Strategy retold: toward a narrative view of strategic discourse. Academy of Management Review, 22(2), 429-452.

Bertero, C., Vasconcelos, F., Binder, M. (2003) Estratégia empresarial: a produção científica brasileira entre 1991 e 2002. Revista de Administração de Empresas, 43, 48-62.

Calas, L., Smircich, M. (1999) Past postmodernism? Reflections and tentative directions. Academy of Management Review, 24(4), 649-671.

Canhada, D. I D., Bulgacov, S. (2011) Práticas sociais estratégicas e resultados acadêmicos: o doutorado em Administração na USP e na UFRGS. Revista de Administração Pública, 45(1), 7-32.

Chia, R. (2004) Strategy-in-Action. Anais... Egos Colloquium, 20, 2004, Eslovênia.

Clark, P. (2007) The commercialization of university research and economic productivity. Higher Education Management and Policy, 19(1), 133-144.

Cunliffe, A. L. (2008) Orientations to social constructionism: relationllay responsive social constructionism and its implications for knowledge and learning. Management Learning Review, 39(2), 123-139.

Fenton, C., Langley, A. (2011) Strategy as practice and the narrative turn. Organizational Studies, 32(9), 1171-1196.

Gergen, K., Thatchenkery, T. (2006) Organizational science and the promisses of postmodernism. In: Hosking, D. M., McName, S. (Org.) The social construction of Organization. Liber\&Copenhagem Business School Press.

Gioia, D., Chittipeddi, K. (1991) Sensemaking and Sensegiving in Strategic Change Initiation. Strategic Management Journal, 12(6), 433-448.

Jarzabkowski, P., Seidl, D. (2008) The role of meetings in the social practice of strategy. Organizational Studies, 29(11), 1391-1426. 
Josemin, G. C. (2011) A perspectiva de estratégias como prática - Explorando a sua aplicabilidade no estudo de uma instituição de ensino superior. Anais... EnAnpad - Encontro da Associação Nacional de Pós-Graduação e Pesquisa em Administração, 35, 2011, Rio de Janeiro - RJ.

Johnson, G., Melin, L., Whittington, R. (2003) Micro strategy and strategizing: towards an activity-based view. Journal of Management Review, 40(1), 3-22.

Kaplan, S. (2007) Strategy as practice: an activitybased approach. Academy of Management Review, 986-990.

Knights, D., Morgan, G. (1991) Corporate strategy, organizations, and subjectivity: a critique. Organizations Studies, 12(2), 251-273.

Kumar, S., Dash, M. K. (2011) Management education in India: trends, issues and implications. Research Journal of International Studies, 18, 16-26.

Maciel, C. de. O., Augusto, P. O. M. (2013) A practice turn e o movimento social da estratégia como prática: está completa essa virada? Revista de Administração Mackenzie, 14(2), 155-178.

Mintzberg, H. (1978) Patterns in strategy formation. Management Science, 24(9), 934-948.

Oliveira, S. A. de, Canuto, K. C, Mussi, F. B. (2009) Práxis e seus mediadores na 'estratégia como prática social': o papel do uso das tecnologias na consolidação da prática estratégica. Anais... EnAnpad - Encontro da Associação Nacional de Pós-Graduação e Pesquisa em Administração, 33, 2009, São Paulo - SP.

Pardini, D. (2005) A formação cultural como construto de ligação entre visão empreendedora e ação estratégica - Uma Análise do Caso Usiminas. Anais... 3Es - Encontro de Estudos em Estratégia da Anpad, 2, 2005, Rio de Janeiro - RJ.

Pereira, L. (2004) Valores e estratégia organizacional: estudo comparativo de casos em órgãos oficiais de turismo. Anais... EnAnpad - Encontro da Associação Nacional de Pós-Graduação e Pesquisa em Administração, 28, 2004, Curitiba - PR.

Pereira, M., Agapito, F. (2005) Afinal, como se formam as estratégias? O processo de formulação estratégica em uma organização do terceiro setor. Anais... 3Es - Encontro de Estudos em Estratégia da Anpad, 2, 2005, Rio de Janeiro - RJ.
Pereira, J. A., Souza, M. C. D. de., Tatoo, L., Oliveira, J. S. de. (2010) Estratégia como prática: um estudo em empresas incubadas de base tecnológica. Anais... EnAnpad - Encontro da Associação Nacional de Pós-Graduação e Pesquisa em Administração, 34, 2010, Rio de Janeiro - RJ.

Pye, A. (2003) Making sense of (the explanatory function of strategizing. Anais... Egos Colloquium, 19, 2003, Copenhagen.

Raschie, A., Chia, R. (2009) Research strategy practices: a genealocial social theory perspective. Organizational Studies, 30(7), 713-734.

Samra-Fredericks, D. (2004) Understanding the production of 'strategy' and 'organization' through talk amongst managerial elites. Culture and Organization, 10(2), 125-141.

Santos, L. L da S., Tureta, C. (2006) A estratégia como uma prática social: em busca do que seja "fazer estratégia". Anais... EnAnpad - Encontro da Associação Nacional de Pós-Graduação e Pesquisa em Administração, 30, 2006, Salvador - BA.

Saraiva, E. V. (2007) Estratégia como construção social: proposta teórico-metodológica. Anais... 3Es - Encontro de Estudos em Estratégia da Anpad, 3, 2007, São Paulo - SP.

Schwandt, T. (2000) Three epistemological stances for qualitative inquiry: interpretivism, hermeneutics, and social construction. In: Denzin, N., Lincoln, Y. (Org.) Handbook of qualitative research. Thousand Oaks: Sage Publications.

Seidl, D. (2003) The role of general strategy concepts in the practice of strategy. Anais... EGOS Colloquium, 19, 2003, Copenhagen.

Smircich, L., Stubbart, C. (1985) Strategic management in an enacted world. Academy of Management Review, 10(4), 724-736.

Souza, C. M. L. de. (2011) Entre o planejamento estratégico formal e informal: um estudo de caso exploratório sobre a prática de estratégia nas organizações. Revista de Administração Contemporânea, 15(5), 855-876.

Spink, M. J. (1999) Práticas discursivas e produção de sentidos no cotidiano: aproximações teóricas e metodológicas. São Paulo: Editora Cortez.

Spink, M. J., Frezza, R. M. (1999) Práticas discursivas e produção de sentidos: a perspectiva da psicologia social. In: Spink, M. J. P. (Org.) Práticas 
discursivas e produção de sentidos no cotidiano: aproximações teóricas e metodológicas. São Paulo: Cortez.

Tureta, C., Rosa, A. R., Santos, L. L da S. (2006) Estratégia como prática social e actor-network theory: uma possível conversação para o estudo da estratégia. Anais... EnAnpad - Encontro da Associação Nacional de Pós-Graduação e Pesquisa em Administração, 30, 2006, Salvador - BA.

Tureta, C., Lima, J. B. de. (2011) Estratégia como prática social: o estrategizar em uma rede interorganizacional. Revista de Administração Mackenzie, 12(6), 76-108.

Valadão, J. A. D., Silva, S. S. S. (2012) Justaposições da estratégia como prática e processo de estratégia: antes da visão pós-processual da estratégia. Revista de Administração Mackenzie, 13(2), 171-195.

Varyani, M., Khammar, M. (2010) A review of strategy-as-practice and the role of consultants and middle managers. 2010. 49 p. Master's Thesis in Design and Construction Project Management Master's Programme - Chalmers University of Technology. Göteborg: Suécia.

Vasconcelos, F. (2001) Safári de estratégia, questões bizantinas e a síndrome do ornitorrinco: uma análise empírica dos impactos da diversidade teórica em estratégia empresarial sobre a prática dos processos de tomada de decisão estratégica. Anais... EnAnpad - Encontro da Associação Nacional de Pós-Graduação e Pesquisa em Administração, 25, 2001, Campinas - SP.

Vasconcelos, F. (2002) Estratégia empresarial e construção social da realidade - $\mathrm{O}$ caso da internet no Brasil. Anais... EnAnpad - Encontro da Associação Nacional de Pós-Graduação e Pesquisa em Administração, 26, Salvador BA.

Vasconcelos, F., Bertero, C. O., Binder, M. P. (2005) Estratégia empresarial: a produção científica brasileira entre 1991 e 2002. In: Bertero, C. O., Caldas, M. P., Wood Jr, T. (Org.). Produção científica em Administração no Brasil. São Paulo: Editora Atlas.

Walter, S. A., Augusto, P. O. M. (2011) A institucionalização da estratégia como prática nos estudos organizacionais. Revista de Administração da USP, 46(4), 392-406.

Weick, K. (1995) Sensemaking in organizations. London: Sage Publications.

Wenyao, F., Watson, D. (2008). (Ed.) National policy on higher education management - collected works of Sino-UK joint programme. London: British Council.

Whittington, R. (1993) What is strategy - and does it matter? London: International Thomson Publishing Company.

Whittington, R., Jarzabkowski, P., Mayer, M., Mounoud, E., Nahapiet, J., Rouleau, L. (2003) Taking strategy seriously: responsibility and reform for an important social practice. Journal of Management Inquiry, 12(4), 396-409.

Whittington, R. (2004) Estratégia após o modernismo: recuperando a prática. Revista de Administração de Empresas, 44(4), 44-53.

Whittington, R., Molloy, E., Mayer, M., Smith, A. (2006) Practices of strategising/organising: broadening strategy work and skills. Long Range Planning, 39, 615-629.

Whittington, R. (2006) Completing the practice turn in strategy research. Organizational Studies, 27(5), 613-634.

Whittington, R. (2007) Strategy practice and strategy process: family differences and the sociological eye. Organizational Studies, 28(10), 1575-1586. 